\title{
CONCEPT OF AUTOMATED MALFUNCTION DETECTION OF LARGE TURBOMACHINERY USING MACHINE LEARNING ON TRANSIENT DATA
}

\author{
Tomasz BARSZCZ, Mateusz ZABARYLLO \\ AGH University of Science and Technology, Krakow, Poland, tbarszcz@agh.edu.pl \\ General Electric Sp. z o.o., Elblag, Poland, mateusz.zabaryllo@ge.com
}

Abstract

Large turbosets constitute a major source of electric energy in the world. They are critical machines which are vulnerable to several malfunctions which can decrease their availability and degrade the operation of the national electric grid system. The best source of data for assessment of the technical state are the transient data, measured during run-ups and coast-downs. The size of this data is very large and its analysis can be only performed by highly skilled vibration experts. The goal of this paper is to propose a method, which can apply Machine Learning for automated fault detection. In order to improve the quality of the learning process the method is accompanied by the 'Digital Twin' approach, where the simplified analytical rotordynamic model is tuned to a particular turboset and used in the learning process.

Keywords: turbomachinery, transient data, machine learning, rotor modelling, digital twin

\section{METODA AUTOMATYCZNEJ DETEKCJI NIESPRAWNOŚCI DUŻYCH TURBOZESPOŁÓW Z ZASTOSOWANIEM METOD UCZENIA MASZYNOWEGO NA DANYCH ZE STANÓW PRZEJŚCIOWYCH}

\section{Streszczenie}

Turbozespoły dużej mocy stanowią znaczną część źródeł energii elektrycznej na świecie. Są to maszyny krytyczne, które są wrażliwe na kilka rodzajów niesprawności. Mogą one obniżyć dyspozycyjność maszyn i wpłynąć negatywnie na prace całego systemu elektroenergetycznego. Najlepszym źródłem danych do oceny stanu dynamicznego są dane ze stanów przejściowych, mierzone podczas rozruchów i odstawień. Są to dane o bardzo dużych rozmiarach a ich analiza może być przeprowadzana tylko przez doświadczonych diagnostów. Celem artykułu jest propozycja metody, wykorzystującej metody uczenia maszynowego (Machine Learning) do automatycznego wykrywania uszkodzeń. W celu podniesienia jakości procesu uczenia metoda została uzupełniona o zastosowanie uproszczonego modelu analitycznego stanu dynamicznego turbozespołu. Model ten jest dostrajany do danego turbozespołu, a następnie stosowany do wygenerowania dodatkowych danych ze stanów przejściowych, które będą następnie użyte w procesie uczenia.

Słowa kluczowe: turbozespół, dane ze stanów przejściowych, uczenie maszynowe, modelowanie wirników

\section{INTRODUCTION}

Large turbosets are the main source of electric energy all over the world. Despite the rapid development of renewable sources, it will remain so at least for the next few decades. They are a critical machines which in case of unavailability can degrade the operation of the national electric grid system. The composition of large turbosets is different for every country. In Poland, the most important part of the turbogenerators are units of 200 MW type (13K215 and its modifications). They are the most frequently encountered large machines in Poland (54 still in operation which constitute $50 \%$ of national power generation capability [1]). The next most important type is the $18 \mathrm{~K} 360$, as there are 16 units of this type in Poland. There are also several new units of a very large power, ranging from $800 \mathrm{MW}$ to $1000 \mathrm{MW}$. Such a structure of the Polish power generation sector is the reason of focusing the research on the $200 \mathrm{MW}$ class turbines first. The method should be general so that it can be applied to other turbines beyond the $200 \mathrm{MW}$.

The turbogenerators vulnerable to several malfunctions. The most important ones are:

- unbalance,

- misalignment,

- oil and steam instabilities,

- bearing overload/ underload,

- pedestal looseness,

- rotor rub.

Any analysis of the dynamic state of the rotor system requires the data. The richest source of such a data are relative vibrations of the shaft within the journal bearing measured by (eddy current probes). The analysis involves several groups of parameters, e.g. broadband features, frequency selective 
features and harmonic vectors. There is a wide literature about vibration data analysis and manifestation of various malfunctions in the vibration signals. The field of rotordynamics was intensively researched from the early works of Jeffcott [4] until modern times. Very good introduction to the subject can be found in the classic book of Bently and Hatch [2]. The interested reader can also refer to the work of Vance [3], where the full course of rotordynamic analysis is given. Another interesting book by Muszynska [4] presents advanced modelling of journal bearing systems and its reaction on most important malfunctions.

Often the availability of the real data from faulty states is limited. This reason has triggered many research in the field of modelling of rotor systems. Complex and accurate models, especially focused on $200 \mathrm{MW}$ class turbines were proposed by Kicinski [5]. His team developed advanced models which implemented FEM (Finite Element Method) approach. Interesting papers applying model based approach were published by Pennacchi et al [6]. Authors presented their experiences with using models for fault detection of turbomachinery. Even when a model structure is known and fixed, it is very important to obtain correct model parameters to enable the model output to follow the real object. The paper by Bachschmid et al discussed model uncertainties and proposes a method for automatic parameter update [7].

With the development of Artificial Intelligence and Machine Learning fields, new possibilities were opened in recent years to further improve the model generation or/ and quality of fault detection. For an exhaustive introduction to the domain of ML the interested reader can refer to the books of Abu Mostafa et al [8] or by Bishop [9]. In general, ML helps to analyze large amounts of data and to perform a number of various tasks. For the fault detection problems, the most useful application of AI is classification where a new set of data is assigned a group, which can refer to the major possible faults and the healthy state. During last years several ML algorithms were developed, e.g. linear classifiers, neural networks, clustering, Bayesian networks, deep networks, Support Vector Machines etc. Often, a task requires a combination of a few methods. Another distinction of ML methods considers the way in which the algorithm is trained. The most popular one is the supervised learning, which allows for quick optimization of an algorithm, provided that there is enough data describing all the possible cases. In machinery diagnostics practice this condition is often hard to fulfill. The other approach is the unsupervised learning, where there is no description of the data. Still, the data can be clustered, i.e. divided into groups of similar properties. Such an approach can be useful for the novelty detection task. It is valuable for the cases when a data from a new machine are being analyzed. In such a case all the (very different) data from all the rotational speeds and loads should be treated as normal. If there is a deviation from a previously known behavior, the user should be notified. With the unsupervised learning, the further involved of a human expert is required.

Since the beginning of the AI, the machinery fault detection was an interesting field of research with a high number of papers being published. Interesting works presenting comparison of different methods was presented by Dou and Zhou [10]. Important problem of robustness of classification is presented in [11]. Often, a combination of a few methods of machine learning and artificial intelligence approach is shown as a successful method [12-19]. However those works involved only ball bearings [22] and were applied either for test rigs [25] or on a small scale machinery [23].

There are few published works, where the ML methods are proposed for a large scale machinery, either using steady state or transient data. Thus, such a method can bring significant benefits to the user. It can reduce the required workload of a highly skilled vibration experts and it can also provide better coverage of the data, as now all the data can be analysed by an algorithm regardless of the availability of the human expert giving the outcome with as little error as possible under disturbed or uncertain data [21], [22]. The ML methods can provide the user with an assessment of the technical state of the machine. The assessment can be done automatically when the new data are available.

The goal of the paper is to propose a higher level method which can properly diagnose turbomachine faults based on transient data within as little as possible involvement from expert engineer. The aim of this concept is to automatically diagnose shaftline equipped in journal bearings during transient state operation of the large turbomachinery. The most accurate information about the dynamic state is delivered by eddy current probes mounted in the bearing and it will be used for further analysis.

This paper is composed of 4 parts. First, in the introduction the current state of the art of both rotordynamics and machine learning is briefly presented. The special attention is given to the problem of automated fault detection in the rotating machinery. The Chapter 2 presents the fundamentals of rotor vibrations with basic analytical models. Practical methods for vibration measurements in large turbosets are presented as well. Typical vibration expert tools are introduced. The Chapter 3 is the main part of the paper and presents the proposal of the method. At this stage of the development the method does not impose any ML algorithm, but presents the larger context of the automated fault detection. The most important considerations are connection to the data source, i.e. online CMS (Condition Monitoring System) and 
enhancement of the method by the usage of simplified analytical model of the shaft line. Such an approach is recently referred as the 'Digital Twin'. The Chapter 4 contains concluding remarks and describes further steps planned to develop and implement the method.

\section{VIBRATION OF LARGE TURBOSETS}

In the power generation critical machinery such as turbo-generators are assumed to run smoothly for the whole lifetime period - often more than 30 years. Especially in large units, which are equipped in oil lubricated hydrodynamic bearings, vibration severity criterion is one of the most essential monitoring parameter as for the machine's mechanical condition. Mechanical vibration is the source which contains most information about the health of the component. In order to properly use the vibration measurement results, the vibration of shaft line must be understood.

The most fundamental concept of estimation of rotating machinery is a model of Jeffcott rotor described by Vance [3] and shown below:

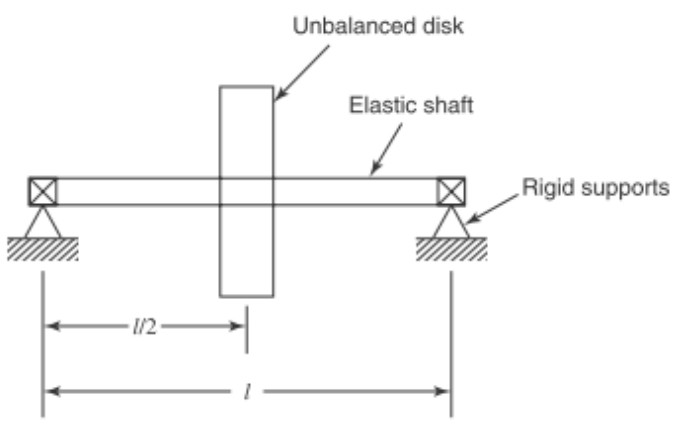

Fig. 1. The Jeffcott rotor model [3]

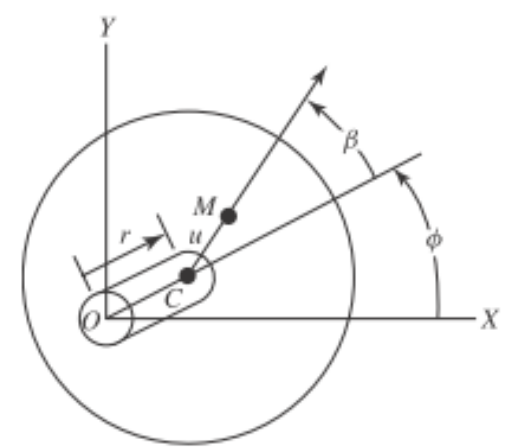

Fig. 2. End view of the Jeffcott rotor [3]

The model assumes that gravity load is neglected, centre of mass of unbalanced disc is at the point $M$ and it is located on massless and elastic shaft. Geometric centre of the disc is in at point $C$ with static unbalance $u$. Shaft bending stiffness is $k$, mass of the disk is $m$, air drag and shaft is approximated by $c$ (viscous damping coefficient), synchronous phase angle is $\beta_{s}$, and synchronous whirling amplitude is $r_{s}$. The rotor is mounted on rigid bearings. The cartesian coordinates system is represented by $X$ and $Y$ axis shown in Fig. 2.
Taking above into account equations of motion for the cartesian coordinate for the model in Fig. 1 and Fig. 2 can be listed as follows [3]:

$$
\begin{aligned}
& m \ddot{X}+c \dot{X}+k X=m \omega^{2} \cos \omega t \\
& m \ddot{Y}+c \dot{Y}+k Y=m \omega^{2} u \sin \omega t
\end{aligned}
$$

With a solution of:

$$
\begin{gathered}
X=\frac{\Phi^{2} u}{\sqrt{\left(\frac{k}{m}-\omega^{2}\right)^{2}+\left(\frac{c \omega}{m}\right)^{2}}} \cos \left(\omega t-\beta_{s}\right) \\
Y=\frac{\Phi^{2} u}{\sqrt{\left(\frac{k}{m}-\omega^{2}\right)^{2}+\left(\frac{c \omega}{m}\right)^{2}}} \sin \left(\omega t-\beta_{s}\right) \\
\beta_{s}=\tan ^{-1}\left(\frac{c \omega}{m\left(\frac{k}{m}-\omega^{2}\right)}\right) \\
r_{S}=\sqrt{X^{2}+Y^{2}}
\end{gathered}
$$

Equations (5) and (6) can be drawn in respect to angular speed of the rotor $₫$. This will provide useful information on behaviour of the rotor during transient state operation i.e. change of rotor speed Fig.3. Analysing Fig. 3 it can be seen that well below critical rotor speed $(\omega=\sqrt{k / m})$ phase angle (phase lag $\beta_{\mathrm{s}}$ ) is in phase with the unbalance force $u$. As rotor reaches its critical speed, whirling amplitude $r_{s}$ reaches its maximum with phase angle reaches $90^{\circ}$. With increasing of rotation speed, phase lag will increase from $90^{\circ}$ up to $180^{\circ}$ which will cause whirling amplitude to reduce after its critical speed range.

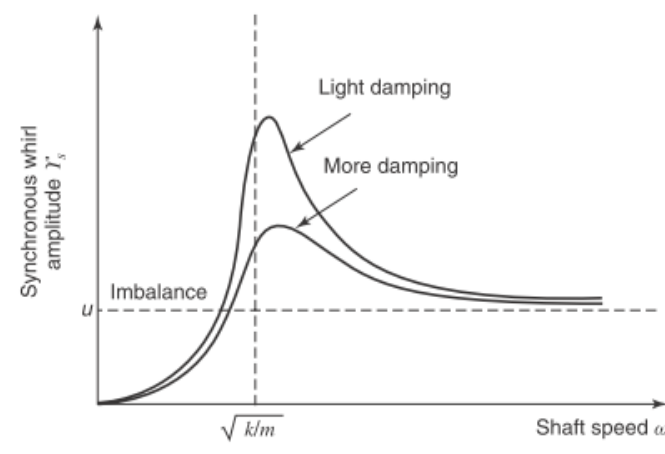

(a)

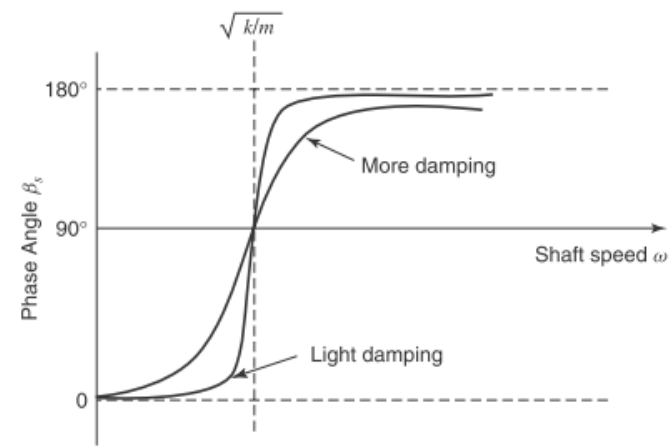

Fig. 3. Amplitude vs. phase during speed change in Jeffcott model for two damping coefficients [3] 
On Fig. 3 in shown that damping coefficient has significant influence of the synchronous response during transient state. In real application synchronous response of the rotor during transient speed operation (i.e. start-up, cast down) is much more complex and is highly influenced by damping factor. This factor is dependent on bearing's oil wedge parameters. Different bearing geometry, oil parameters and other factors (eg. assembling technology, etc.) can produce different wedge properties on the same machine and as an result exhibit different characteristics close to its critical zone - see Fig.4. The Fig. 4 presents Bode plot of a real turboset after modification of bearing parameters.

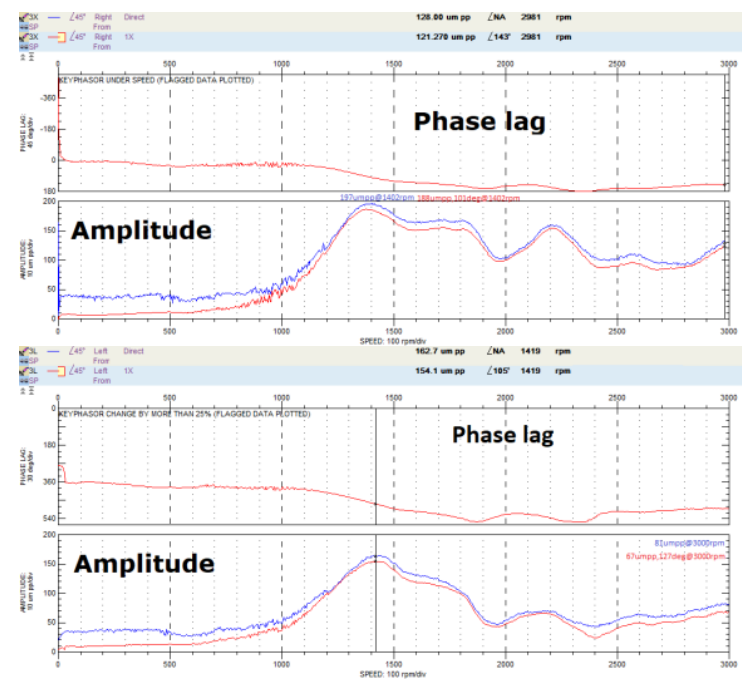

Fig. 4. Amplitude and phase vs revolutions

(Bode plot) from that same probe before (top) and after (bottom) change in the bearing parameters

As it shown in Fig. 4, proper bearing's parameters has an important influence on whether the machine's dynamic state would be accepted or not for long time safe operation. During start-up (Fig. 4 top) it was decided to correct the bearingrotor system parameters to meet an "A" zone acc. to ISO 20816-2:2017 (former ISO 7919-2:2009) standard. After improving bearing-rotor system parameters criteria were met - Fig. 4 bottom.

The real machines are much more complex than the basic Jeffcott model. They consist of several rotors, supported often with different bearing's types. Fig. 5 presents a shaftline of a 200MW type. It consists of 4 to sometimes 5 rotors, and the complexity of the analysis increases significantly.

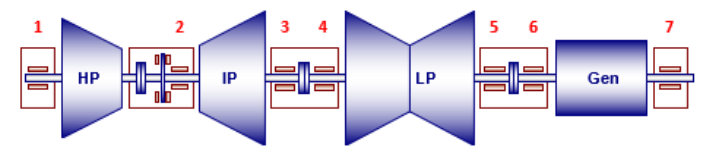

Fig. 5. Schematic of shaft line of the $200 \mathrm{MW}$ type turboset
Large turbogenerators are considered as the most important machines in power generation process. Thus, they are equipped in eddy current probes for both protection and monitoring of the unit.

For the case of large turbomachinery which are rigidly coupled with generator (e.g. Fig. 5) passing through transient state, the most common excitation force is one which comes from residual unbalance. It excites the system at the frequency $1 \mathrm{X}$ (first harmonic of the rotational speed) [2], [3]. For this purpose synchronous waveforms and theirs processed features (conjunct with tacho reference signal - once per revolution) will be taken into account (including sub-synchronous component and a first few harmonics [2]).

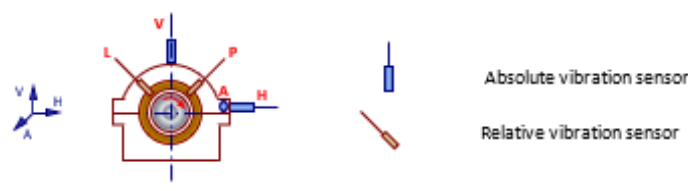

Fig. 6. Measurement's arrangement on a bearing

Information about this behaviour can be provided by two types of sensors. Such an arrangement can provide a lot of information from diagnostic and analytical point of view. The two types of vibration sensors are: relative vibration sensor mounted in the bearing and absolute vibration sensor mounted on the bearing pedestal as depicted in Fig. 6. Relative vibration sensors measure the distance from its tip to the shaft which rotates inside the bearing. Absolute vibration sensor measure the velocity or acceleration of the bearing pedestal. Machine with 4 rotors supported on 7 bearings will typically have 14 eddy current probes and several absolute vibration sensor which complement the information about the vibration behaviour. Orthogonal arrangement of the relative probes enables to analyse shafts' orbit [2] at each bearing, and during transients each probe can exhibit support anisotropy [4].

The raw vibration signals are very complex and have very large size. Therefore, there are a few types of signal features, which allow to describe machine dynamic state such as: overall level of vibration, both relative (measured in $\mu \mathrm{m}_{\mathrm{pp}}$ or $\mu \mathrm{m}_{0 \mathrm{p}}$ ) and absolute (measured in RMS - root mean squared, or 0-pk - zero-peak). Other commonly used features are $1 \mathrm{X}, 2 \mathrm{X}$ and subsynchronous [2]. For the harmonic features it is important to track both amplitude and phase. All the features are derived from the displacement or velocity sensors, as described above.

Transient data are, next to steady state data, a diagnostic tool, to assess the dynamic state of the machine [21]. Steady state operation is condition at the rated speed and within load operation. Transient states are: start-up, shut-down and passing through the resonance ranges. Transient data allow to 
determine parameters which aren't visible during the nominal speed operation, such as bearing parameters such as stiffness [24] and natural frequencies. These data can be used to determine both rotor and structural frequencies of the bearing pedestals [4]. Rubs and rotor cracks can be much easier identified during transients [2], [4], [20], [25]. Machines equipped with hydrodynamic bearings can also develop an oil whirl/whip phenomenon, when the oil film behaves like the oscillating dynamic system [4]. The Fig. 7 depicts a real case, when the oil whirl was encountered during the machine run-up which forced trip (forced outage) of the turbine.

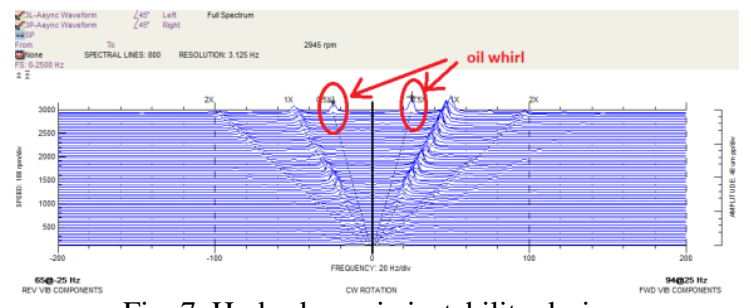

Fig. 7. Hydrodynamic instability during

start-up of $200 \mathrm{MW}$ unit (cascade spectrum plot)

In the example shown on Fig. 7 the fluid film instability (oil whirl) develops near to FSNL (Full Speed No Load) operation (Fig. 7 - top plot). Using the full spectrum plot, presence of an oil whirl can be seen in two directions. The severity of oil whirl is apparent on the Trend plot (Fig. 7 bottom). The vibration amplitude during oil whirl $\left(280 \mu \mathrm{m}_{\mathrm{pp}}\right)$ is near to the clearance boundaries between shaft and bearing (approx. $320 \mu \mathrm{m}_{\mathrm{pp}}$ ) which can cause damage to the components of the machine.

During each transient state (both start-up and coast down) different parts of coupled shafts pass through their critical rotational speed region. It is typical that some shafts operate above their first mode (HP, IP part), and some even above the second mode (Gen, sometimes LP) which makes analysis much more complex and prone to error.

Table 1. Theoretical critical speeds for the one of the 200 MW unit for the ideally stiff support assumption. Data from commercial dynamical system

\begin{tabular}{|r|r|r|}
\hline Critical & $\begin{array}{c}\text { Rotational } \\
\text { speed } \\
\text { [rpm] }\end{array}$ & Affected rotor \\
\hline I & 882 & Generator 1. mode \\
\hline II & 2195 & Turbine - High Pressure \\
\hline III & 2580 & Generator 2. mode \\
\hline IV & 3415 & Turbine - Low Pressure \\
\hline V & 3514 & Turbine - Intermediate Pressure \\
\hline
\end{tabular}

During each transient the turboset which consists of 4 rotors in such an arrangement (Fig. 5) will pass through at least three critical speeds listed in the Table 1 (I - III). The critical speeds no. IV and no. $\mathrm{V}$ are above operating speed range and they will not affect vibration during the transient states.
Monitoring of vibration signal features during transient operational states is a powerful source of information. Unfortunately, such an analysis requires a skilled expert. An automated method for such an analysis will improve the safety of operation and decrease the labour cost of the machinery maintenance.

\section{PROPOSAL OF THE METHOD}

The main part of the paper is description of the method which can properly diagnose turbomachinery faults. The method was developed with following assumptions:

- uses relative vibration data,

- transient data are the main source of information,

- signal estimates are used and not the raw vibrations,

- the data are supported by the 'Digital Twin' data,

- supervised learning will be adopted.

The complete flowchart of the method is presented in the Fig. 8. Main source of the data is the real machine (Physical object) on the top right with eddy current probes. Typical 200 MW turbine has 14 such relative vibration sensors. A machine can be equipped with online monitoring system or with a portable one. Each of such systems collect raw vibration data and calculates the signal features. They become the 'Processed Data'. This data are much smaller in size and retain all the important information about the critical speeds and damping, which are essential for the fault detection. Both sources should store the data in a known, uniform data format, i.e. they are converted to the dataset format.

The common problem with application of ML methods for machinery diagnostics is insufficient amount of data. Even if the online data is available (as it is the case recently with the proliferation of the online CMS), this data is in almost $100 \%$ coming from a healthy technical state. There is sometimes some faulty data available, but comparison with the scope of potential faults (in different magnitudes), the feature space is practically empty. We decided to tackle this limitation with the so-called 'Digital Twin' approach, which is a simplified numerical model. As presented in Fig. 8, The Analytical Model (top left) is a 1D lumped parameters model of the machine which consist of an $\mathrm{n}$ sections depicted at fig. 8. Sections are realized as lumped mass points at the point of section's centre. Particular sections of the rotor model are treated as a mass of specified inertia dependent on dimensionality of the section attached across massless rotor line. 


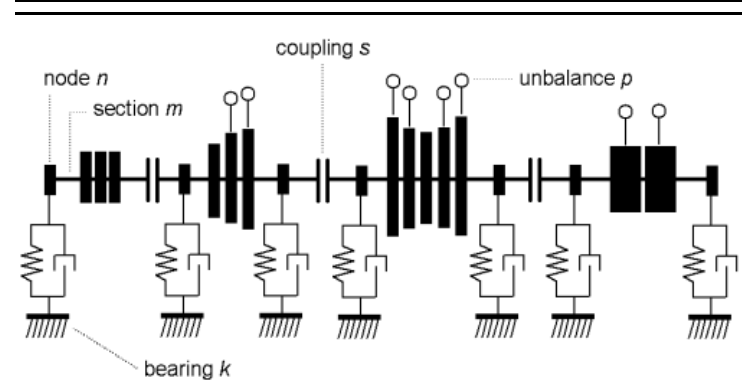

Fig. 8. Simplified n sectioned, lumped mass model of $200 \mathrm{MW}$ unit.

The main model features are:

different stiffness in both translational and rotational movements (dependent on applied material);

- bearings with non-linear characteristics;

- sections of anisotropic area (anisotropic rotor simulation - crack rotor simulation);

- ability to simulation of a transient state (startup, cast-down);

- simulation of different malfunction (unbalance response for different locations across the shaftline, fluid inducted instabilities (oil whirl/whip), misalignment, etc).

Initial tests of the model were performed at the test rig. The simple rotor system (consisted of a shaft with two discs and two supports). This test rig geometry was implemented in a model. The vibration measured on the rig and obtained from the model were in good agreement (Fig. 9).

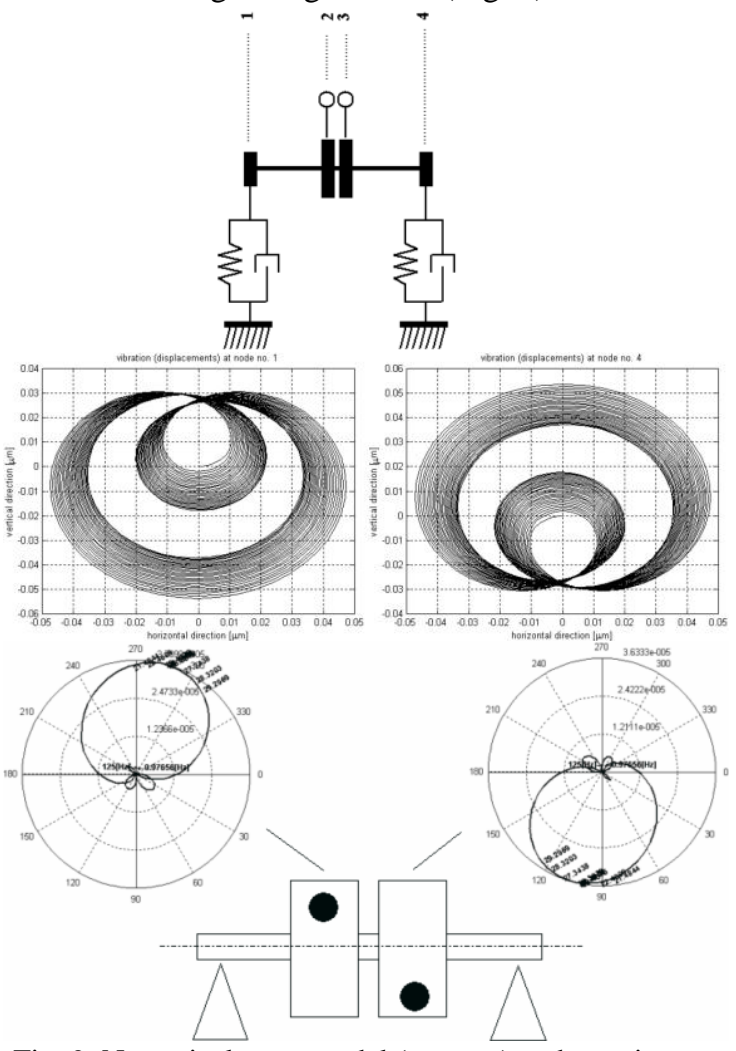

Fig. 9. Numerical rotor model (top two) and test rig measurements (bottom two).
There are, however limitations of the presented simplified modelling approach:

- discrepancies in outcome data due to insufficient numbers of sections can cause ;

- impossibility to model e.g. steam unbalance due to difference in feeding nozzle boxes, as it is not a phenomenon which can be modelled in 1D only.

The "Digital Twin" model is much simpler and easier to handle than the complex FEM model. Since the output of the model are only the processed data, it needs only to be as accurate as to generate accurate enough signal features (pp, rms, gap, 1X, 2X, sub). This features are next stored in the same format as the data from the physical object. Accuracy requires that different types of journal bearings should be implemented in order to properly simulate the machine behaviour during transients. For example the modernized designs of 200MW type turbines includes different types of journal bearings such as cylindrical bearings with 1 oil inlet ( 1 wedge bearing), an elliptical bearings with one oil wedge and an Y-type bearing (bearing no. 1). This requirement makes modelling more complicated and forces to take all of above mentioned types into account in order to receive proper simulation's data. Still, only the lump parameters models will be used.

Simulated data would be transposed/transferred into a set of processed data with features like: unfiltered vibration amplitudes (in $\mu \mathrm{m}_{\mathrm{pp}}$ ), synchronous response of rotor system in all bearings (1X amplitude and phase lag), subsynchronous response (near the $0.5 \mathrm{X}$ ), and supersynchronous part of signal (like $2 \mathrm{X}, 3 \mathrm{X}$ etc.). This kind of data would create a basic data set for training purposes marked as the "OK state". Altering some model features (like bearing's parameters, adding unbalance, etc.) a full malfunction data will be prepared as the training data set, which than be used to train the ML algorithm.

There are a few ML algorithms which will be taken into consideration:

- $\quad$ kNN (k Nearest Neighbour);

- SVM (Support Vector Machines).

The "kNN" model is a "lazy" (learning from data) non-parametric classification algorithm. It makes no assumptions about data distribution and it doesn't use training data to perform any generalization. It measures how new data are far from training data set.

The SVM algorithm tries to produce optimal hyperplane from labelled data provided as a training data set to define decision boundaries. It is often a model of choice for a classification task, as in the proposed problem.

With the data from both real object and the Digital Twin ready, these files are sent to the Feature extraction module (Fig. 10, middle), which performs all the steps required to prepare the data for ML algorithms. The scope of the pre-processing 
depends on a method used, but typically contains validation, detection of bins referring to the operational states, so that only transient data are processed further. Most methods require normalization of features to be performed. If required, orthogonalization can be also applied to the data at this point.

The proper ML algorithm is applied after this step (Fig. 10 bottom right). For simplicity the Fig. 10 depicts the real data as the testing data and the simulated data as the training data. In reality, however, these both types can (ad if possible should) be mixed so that the better quality of training can be achieved. The proposed method is not restricted to any particular ML method and many algorithms can be applied here. This will be the subject of further research.

The final step of the method (Fig. 10, bottom left) is the Algorithm results box. It is composed of validation of the results, and it is a heuristic step designed to avoid systematic errors in classification. The next one is the data presentation, where the raw output from an ML algorithm can be analysed and the expert can monitor performance and efficacy of the algorithm. The data are finally sent to the Diagnosis proposal module. This module is meant to be used by plant operators. It should

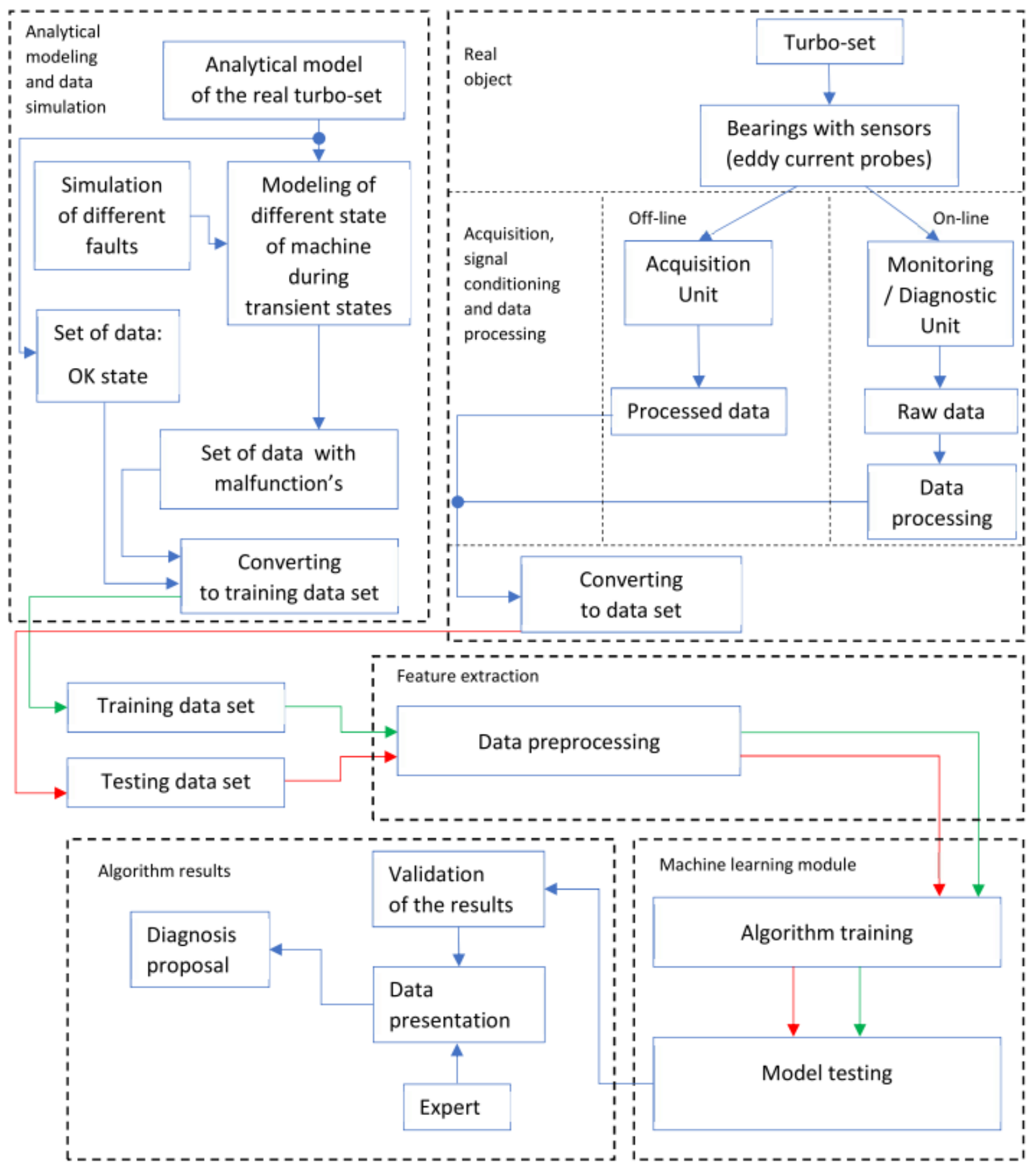

Fig. 10. Flowchart of the proposed fault detection method 
have only a limited functionality, where the estimated technical state is presented for the user. The proposal will be accompanied by only the most important data, e.g. timestamp, speed and load conditions. The final design of this module will be completed after several rounds of discussions with plant operators. It should also include the automatic reporting functionality.

Thus, the method will assign the data to one of following states: OK, unbalance, rubs, oil wirl/whip, misalignment and other known faults. It is important also to include the state 'unknown'. The data can be assigned to this state if the current set is too far away from any known state and can happen if a new fault is encountered. Such a data can be later used for retraining of the system and adding the new fault type.

\section{CONCLUSIONS}

The theory of rotating shaft vibration is well developed. It starts from the fundamental Jeffcott model and develops into very sophisticated models of multi rotor systems. Still, despite the development of signal processing and machine learning techniques, there are no proposals of methods, which propose to automatically analyse the fundamental signals features collected during the transient state. The paper proposes such a method. The data can be acquired in large amounts using an interface to commercial online CMS systems. The key problem in Machine Learning is lack of sufficient amount of data to properly train and validate a model. The proposed concept uses a simplified numerical model of the shaftline vibration. The model is then used to simulate data from transient states, including different malfunctions. The success of the method will depend on the ability of the model to properly reflect the machine vibrations. The approach can be used with many ML algorithms, as there are no assumptions towards any particular model. These steps will be the subject of further research.

\section{REFERENCES}

1. Baranowski A, Chmiel J, Ciura Sz. The future of conventional power industry in Poland - report of discussion panel. Silesian Electrical Journal. 2017;134:12-19. Polish.

2. Bently D, Hatch CT. Fundamentals of Rotating Machinery Diagnostics. 1st ed. Canada. 2002

3. Vance JM. Rotordynamics of turbomachinery. Wiley. 1988.

4. Muszyńska A. Rotordynamics. 1st ed. USA; 2005.

5. Kiciński J. Dynamika wirników i łożysk ślizgowych. Polish (Dynamics of shafts and hydrodynamic bearings). 2005.

6. Pennacchi P, Vania A, Chatterton S. Identification of mechanical faults in rotating machinery for power generation. IEEE International Symposium on Industrial Electronics. 2010.

https://doi.org/10.1109/ISIE.2010.5637771
7. Bachschmid N, Pennacchi P, Chatterton S, Ricci R. On model updating of turbo-generator sets. Journal of Vibroengineering. 2009;11:379-391

8. Abu Mostafa Y. Magdon-Ismail M, Lin HT. Learning From Data. AML Book. 2012.

9. Bishop CM. Pattern recognition and machine learning. Springer. 2011.

10. Dou D, Zhou Z. Comparison of four direct classification methods for intelligent fault diagnosis of rotating machinery. Applied Soft Computing. 2016; 46:459-468

https://doi.org/10.1016/J.ASOC.2016.05.015

11. Fawzi A, Fawzi O, Frossard P. Analysis of classifiers' robustness to adversarial perturbations. Mach Learn. 2018:107:481-508. https://doi.org/10.1007/S10994-017-5663-3

12. Shen Ch, Wang D, Kong F, Tse PW. Fault diagnosis of rotating machinery based on the statistical parameters of wavelet packet paving and a generic support vector regressive classifier. Measurement. 2013. 46:1551-1564. https://doi.org/10.1016/J.MEASUREMENT.2012.12. 011

13. Zhong JH, Wong PK, Yang ZX. Fault diagnosis of rotating machinery based on multiple probabilistic classifiers. Mechanical Systems and Signal Processing. 2018;108:99-114. https://doi.org/10.1016/j.ymssp.2018.02.009

14. Haidong S, Hongkai J, Huiwei Z, Fuan W. A novel deep autoencoder feature learning method for rotating machinery fault diagnosis. Mechanical Systems and Signal Processing. 2017;95:187-204. https://doi.org/10.1016/i.ymssp.2017.03.034

15. Deng L, Zhao R. A vibration analysis method based on hybrid techniques and its application to rotating machinery. Measurement. 2013;46:3671-3682. https://doi.org/10.1016/J.MEASUREMENT.2013.07. 014

16. Liu Z, Guo W, Hu J, Ma W. A hybrid intelligent multi-fault detection method for rotating machinery based on RSGWPT. KPCA and Twin SVM, ISA Transactions. 2017;6:249-261. https://doi.org/10.1016/j.isatra.2016.11.001

17. Jia F, Lei Y, Lin J, Zhou X, Lu N. Deep neural networks: A promising tool for fault characteristic mining and intelligent diagnosis of rotating machinery with massive data. Mechanical Systems and Signal Processing. 2016;72-73:303-315. https://doi.org/10.1016/j.ymssp.2015.10.025

18. Li W, Zhu Z, Jiang F, Zhou G, Chen G. Fault diagnosis of rotating machinery with a novel statistical feature extraction and evaluation method. Mechanical Systems and Signal Processing. 2015;5051:414-426. https://doi.org/10.1016/j.ymssp.2014.05.034

19. Khosravifar B, Bouguessa M. Using Support Vector Machines for Intelligent Service Agents Decision Making, P. Perner (Ed.): MLDM 2016, LNAI 9729. 2016:73-87. https://doi.org/10.1007/978-3-31941920-6 6

20. Khadersab A, Dr.Shivakumar S. Vibration analysis techniques for rotating machinery and its effect on bearing faults. Procedia Manufacturing. 2018:20 247-252. https://doi.org/10.1016/J.PROMFG.2018.02.036

21. Fu C, Ren X, Yang Y, Xia Y, Deng W. An interval precise integration method for transient unbalance response analysis of rotor system with uncertainty. 
Mechanical Systems and Signal Processing. 2018;107:137-148.

https://doi.org/10.1016/j.ymssp.2018.01.031

22. Li C, Cabrera D, Oliveira JV, Sanchez RV, Cerrada M, Zurita G. Extracting repetitive transients for rotating machinery diagnosis using multiscale cluster gray infogram. Mechanical Systems and Signal Processing. 2016;76-77:157-173. https://doi.org/10.1016/j.ymssp.2016.02.064

23. Antoni J. The infogram: Entropic evidence of the signature of repetitive transients. Mechanical Systems and Signal Processing. 2016;74:73-94. https://doi.org/10.1016/j.ymssp.2015.04.034

24. Kalita M, Kakoty SK. Analysis of whirl speeds for rotor-bearing systems supported on fluid film bearings. Mechanical Systems and Signal Processing 2004;18:1369-1380.

https://doi.org/10.1016/j.ymssp.2003.09.002

25. Torkhani M, May L, Voinis P. Light, medium and heavy partial rubs during speed transients of rotating machines: Numerical simulation and experimental observation. Mechanical Systems and Signal Processing. 2012;29:45-66.

https://doi.org/10.1016/j.ymssp.2012.01.019

Received 2018-08-25

Accepted 2018-11-29

Available online 2018-12-17

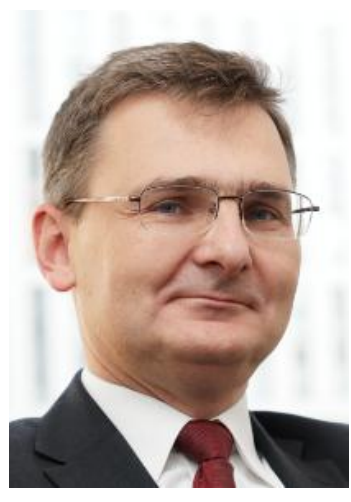

dr hab. inż. Tomasz

BARSZCZ, prof. AGH

Graduate of Electronic Eng at Politechnika Gdańska (1993r.). Received PhD in mechatronics in $1997 \mathrm{r}$. (AGH). Has long experience of working with power generation companies, e.g. $\mathrm{ABB}$ and ALSTOM. Author of over 200 papers and books on machinery diagnostics. Monitoring systems developed under his supervision were installed on several hundred machines worldwide.

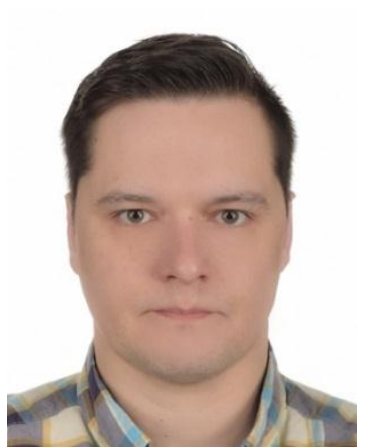

mgr inż. Mateusz

ZABARYLLO

Graduate of Electronic Eng at Politechnika Gdańska (2008). Has extensive practice in applied diagnostic (since 2009). Currently works in GE in Power sector (former ALSTOM Power). He supervised shaftline and bearings assembly in both newly commissioned and repaired/ modernized machines across the Poland and abroad. $\mathrm{He}$ assists commissioning of large turbomachinery by vibration's measurements, analysis, expertise and on-site balancing. 